\title{
Representation of physical activity domains and sedentary behaviors across categories of gender and disability in children's TV cartoons
}

\author{
Sandra Gans-Segrera ${ }^{1}$, Javier Molina-García², Vladimir E. Martínez-Bello ${ }^{*}$
}

ORIGINAL ARTICLE

\begin{abstract}
Television (TV) cartoons could reflect and shape social values about children's health-related behaviors. The main aim of this study is to analyze the portrayal of physical activity (PA) domains in the most popular Spanish children's television (TV) cartoons. It is performed a content analysis of each scene following a coding scheme. The sample selected included the five most popular children's TV cartoons for the 2013-2014 period in Spain. Our results show a large gap between the modest representation of different PA domains compared to the overwhelming depiction of sedentary behaviors. We do not find evidence of males and females participating equally in a variety of PA domains, and we fail to identify any characters with disabilities, reinforcing evidence on their invisibility in different media. Current children's cartoons in Spain are not adequate regarding promoting healthy behaviors related to PA. While policy makers need to work on limiting sedentary time in pre-schoolers, children, teachers, and parents should be encouraged to develop their critical thinking about the under-representation of health-related behaviors-including PA-on children's TV cartoons. The study further contributes to the scientific literature by shedding light on the typical health-related behaviors coded in analyses of children's cartoons.

Keywords: physical activity, cartoons, healthy behaviors, gender, disability.
\end{abstract}

\section{INTRODUCTION}

The lack of physical activity (PA), together with the prevalence of sedentary behaviors (SBs) in young people, is a major public health problem worldwide (Hallal et al., 2014). The ecological perspective on health promotion posits that social and environmental factors influence children's behavior (Sallis \& Owen, 2015), highlighting the importance of nonbiological factors on children's health. Some researchers have applied various paradigms and methodologies to explain the reasons for the high levels of physical inactivity and SBs in children. For instance, one study assessed a sample of episodes of The Simpsons, observing that messages related to physical exercise/fitness made up only about $1 \%$ of all health-related content (Byrd-Bredbenner, 2004). Recently, O'Reilly-Duff et al. (2018) demonstrated that PA is portrayed infrequently in television programs aimed at young adolescents.

On the other hand, studies on North American advertisements have shown that $48.6 \%$ of food ads showed some type of PA (Folta et al., 2006) and that health-related content of food advertisement during children's television programming did not portray PA in a positive light (Outley \& Tadesse, 2006). In addition, most food products that are advertised on Saturday morning television (TV) do not comply with nutritional guidelines for a healthy diet, and $47 \%$ of the sampled advertisements had implicit PA messages (Batada et al., 2006).

\footnotetext{
Manuscript received at January $31^{\text {th }} 2018$; Accepted at October $6^{\text {th }} 2018$

${ }^{1}$ Independent researcher, Valencia, Spain

${ }^{2}$ AFIPS research group, Department of Musical, Visual, and Corporal Expression Teaching, Faculty of Teaching. University of Valencia, Valencia, Spain

${ }^{3}$ Body, Movement and Curricular Practices - COS research group, Department of Musical, Visual, and Corporal Expression Teaching, Faculty of Teaching. University of Valencia, Valencia, Spain

* Corresponding author: Department of Musical, Visual, and Corporal Expression Teaching, Faculty of Teaching. University of Valencia, Avda. dels Tarongers, 4, 46022 Valencia, Spain E-mail: vladimir.martinez@uv.es
} 
Recently, Davis (2016) found that $47.6 \%$ of sample commercials were for unhealthy food and none was for healthy food and drinks. In China, Chang et al. (2018) found that the majority of TV spots advertised products with poor nutritional content and had a potential to mislead audiences concerning products' actual nutritional value.

According to the limited literature, TV is a crucial environmental factor that can affect children's behavior, not only because watching TV requires very low energy expenditure (Cardon et al., 2016), but also because it can present negative behavioral messages that could influence PA and sedentarism in children.

Concerning gender representation in children's programming, research has long explored differences in messages targeted to boys and girls, with early studies finding that girls were portrayed as less active and noisy as well as more childlike, with fewer positions of responsibility compared to boys (Streicher, 1974). Likewise, children's cartoon series on both network and cable channels in the United States have been shown to depict occupational differences between male and female characters (Thompson \& Zerbinos, 1995).

Recent studies revealed that across educational and non-educational children's TV programming, there were significantly more male characters than female characters (Martin, 2017). For instance, in a content analysis study of popular TV shows among adolescents in North America, authors found that male characters were involved in a larger proportion of PA incidents than female characters, and males were more likely to engage in PA for competitive sport (Gietzen et al., 2017). In India, Rozario et al. (2018) found on children's programming that more males than females were cast in all the character roles except in the role of the protagonist's family member, in which both genders were cast equally. Research in Turkey has also reported that male characters were much more likely to be shown doing exaggerated physical movements than female characters (Kalayc, 2015).

On the other hand, the social model of disability suggests that bodily differences are not the key to discrimination and disadvantage but rather the political, social and economic framing of these differences (Saunders, 2004). According to Kearney (2011), the exclusion of people with disabilities is not natural; rather it is a phenomenon that is constructed socially and culturally through human interactions. Taking into account that children with disabilities are among the world's most stigmatized and excluded children (UNESCO, 2017), media representations designed to teach young children about disabilities need to attend to explicit as well as implicit representations of children with disabilities. Martínez-Bello and Molina-García (2016) argued that the imbalance in the representation of disability in the various contexts where PA takes place in the visual representations is symptomatic of the broader exclusion of disabled people across society.

With regard to disability representation in children's programming, in 2006, in the United States, Bond (2013) found on children's television programming that characters with a physical disability were under-represented, but the majority of characters with a physical disability were depicted as morally good, attractive, and satisfied with life, suggesting that children are exposed to through television programming tended to be shown in a positive light. In the same line, Saito and Ishiyama (2005) found in prime-time TV dramas in Japan, that only $1.7 \%$ of the characters analyzed had a disability, all of whom were adults. Furthermore, some authors have shown that children's animated television programs reinforce stereotypes promoting a hegemonic conception of able-bodiedness related to age (Robinson \& Anderson, 2006).

The scientific community has suggested that children under six years old should watch no more than two hours of television a day (e.g., American Academy of Pediatrics, 2016). In Spain, research has shown that only $43.9 \%$ of young children comply with guidelines recommending; on average, they spend 65.6 minutes per weekday and 122 minutes per weekend day in front of a television screen (De Craemer et al., 2015). Furthermore, $88.8 \%$ of young Spanish children did not comply with the 
recommended 120 minutes/day of moderate to vigorous PA (Torres-Luque et al., 2016). Given that more TV time on weekend days is significantly associated with higher body mass index (BMI) in girls but not in boys (Cardon et al., 2016), it is important to understand what messages about PA are being disseminated by children's TV cartoons, including any powerful and negative messages about SB.

While teachers and pre-service teachers recognize that children's books and other printed curricular materials are essential resources that transmit messages (Blumberg, 2015), there is scant research on the PA and health-related SBs depicted in children's TV cartoons. Moreover, few authors have examined what PA patterns are predominantly transmitted to child learners. We believe it is of great interest to both teachers and families to evaluate the implicit messages in children's cartoons in light of current public health recommendations. Therefore, the main aim of this study is to analyze how PA domains are represented on the most popular children's TV cartoons in Spain. In addition, gender, the presence of a disability and group composition, are considered in this analysis.

\section{METHOD}

\section{Participants}

To obtain a sample of Spanish children's cartoons, we identified the children's programs in Spain with the most viewership according to the Barlovento Comunicación (Barlovento Comunicación, 2014). We selected five children's cartoons for analysis based on three criteria: that the cartoons were presented in Spanish, screened in Spain between 2013 and 2014, and were included among the top 10 most viewed TV cartoons by children during that time period. The sample selected included the five most popular children's cartoons for the 20132014 period in Spain: Sponge Bob, Peppa Pig, Penguins of Madagascar, Doraemon and Regular Show.

We then followed a simple random sampling procedure, analyzing each program at the level of the individual scene (defined as a sequence of related animations with no change in location or temporal break, as in previous studies on children's TV programs [Barner, 1999]). Specifically, we coded each scene according to the PA domain, characters' age and gender, group composition, location, and presence of a disability (Table 1). We selected the content sample using the methods presented by Baker et al. (2007), numbering individual scenes and using a table of random numbers to select an initial sample. This method ensured that each scene had the same probability of being chosen for the final sample and that a representative sample could be taken from the total population. Using a confidence level of $99 \%$ and a margin of error of $6 \%$, we obtained a sample of 50 episodes from five cartoons were analysed. After taking a count, the total number of scenes in these 5 children's cartoons totalled 2843 minutes. We again used a random numbers table to select 133 scenes from the total sample, recording the most prominent characters or group of characters for each scene.

\section{Measures}

The definitive scene-analysis procedure was performed using a quantitative content analysis method (Krippendorff, 2004; Outley \& Taddese, 2006). We performed an analysis of each scene following a coding scheme constructed by the research team, based on categories and indicators used previously (Barner, 1999; Martínez-Bello \& Molina-García, 2016). Two experts independently reviewed the scheme, which we revised based on their feedback. Within the body of literature on health promotion, PA is considered to be a complex set of behaviors and is usually evaluated taking into account the settings or domains where activities occur (Hnatiuk et al., 2014). The main domains of active living are leisure-time PA (e.g., exercise, sport, etc.), occupational PA, household activity (e.g., housework, gardening, etc.), and active commuting (e.g., walking and biking to school). SBs are also commonly assessed as an additional domain and usually involve sitting or lying down. Therefore, the final coding scheme had four categories: PA domains (including SBs), gender, group composition, and disability. We coded each unit 
of analysis (scene) by choosing one indicator from each of the categories (Table 1). Of note, we developed indicators and operational definitions of the PA domains, taking into account previous studies promoting $\mathrm{PA}$ and analyzing SB in young people (Bauman et al., 2006; Marshall et al., 2002). Sedentarism was defined as any sitting or supine activity performed while awake and involving energy expenditure of 1.5 metabolic equivalents (METs) or less (Tremblay et al., 2017).

\section{Procedures}

An observational group of coders made up of the first author and two additional researchers, performed the scene analysis using a triangulation method (see for example Lambert, 2003). The coders had not taken part in building the coding scheme and received training in its use in accordance with previous studies (Barner, 1999; Martínez-Bello \& Molina-García, 2016). During the practice coding, reliability was monitored and informally assessed. The principal author was trained over two weeks in order to clarify all steps in the process. On the first day, the lead investigators explained the study objectives and the coding process, and the first author checked the categories and indicators in the coding scheme for understanding. Each scene ( $>1$ second) was played on a personal computer that also showed the list of indicators; the lead author analyzed only the most prominent characters or group of characters and as long as they were performing human activities.

Table 1

Coding scheme for analysis

\begin{tabular}{|c|c|c|}
\hline Categories & Indicators & Descriptions \\
\hline \multirow{5}{*}{$\begin{array}{l}\text { Physical activity } \\
\text { domains }\end{array}$} & $\begin{array}{l}\text { 1. Sedentary behavior or low } \\
\text { activity }\end{array}$ & $\begin{array}{l}\text { 'Awake' activities when sitting, lying or standing that } \\
\text { involve low energy expenditure. }\end{array}$ \\
\hline & 2. Active commuting & $\begin{array}{l}\text { Physical activities, including cycling or walking, as a } \\
\text { way to get to places. }\end{array}$ \\
\hline & 3. Occupational activity & Physical activities through work or occupations. \\
\hline & $\begin{array}{l}\text { 4. Leisure-time } \\
\text { activity }\end{array}$ & $\begin{array}{l}\text { Physical activities for exercise or recreation that can } \\
\text { be organised, such as team or individual sports, or } \\
\text { non-organised, such as traditional games or } \\
\text { recreational sports. }\end{array}$ \\
\hline & $\begin{array}{l}\text { 5. Household } \\
\text { activity }\end{array}$ & $\begin{array}{l}\text { Physical activities in a household setting such as } \\
\text { gardening or child minding. }\end{array}$ \\
\hline Gender & $\begin{array}{l}\text { 1. Male } \\
\text { 2. Female } \\
\text { 3. Group of females \& males }\end{array}$ & $\begin{array}{l}\text { The scene shows one or more people whose basic } \\
\text { characteristics represent males or females based on } \\
\text { clothing, hairstyle, presence or absence of facial hair, } \\
\text { physical stature and other distinguishing } \\
\text { characteristics. }\end{array}$ \\
\hline Group composition & $\begin{array}{l}\text { 1. Solitary } \\
\text { 2. Group }\end{array}$ & $\begin{array}{l}\text { The scene shows a single person or a group with } \\
\text { males, females or mixed gender. }\end{array}$ \\
\hline Disability & $\begin{array}{l}\text { 1. Non-disability } \\
\text { 2. Disability }\end{array}$ & $\begin{array}{l}\text { The scene shows one or more people whose } \\
\text { characteristics represent a physical, sensorial or } \\
\text { mental impairment. }\end{array}$ \\
\hline
\end{tabular}

In order to monitor coder reliability, the main author discussed the coding choices for every 20 scenes with the other two researchers, re-coding any episode if necessary. In total, these three investigators analyzed $30 \%$ of the sample. After playing each scene, the observational group took one to three minutes to select the corresponding indicators. When it was not possible to reach an agreement, they coded the category as unclear. During training, the group resolved any discrepancies and refined the coding criteria; after training, they coded each episode.

\section{Statistical analysis}

We performed a Pearson's chi-square $(x 2)$ test in order to analyse the relationship between the PA domain represented in the scenes and the dependent variables of gender, group composition, and presence of disability of the featured subjects. We constructed a contingency 
table using the PA domain as an independent variable against these dependent variables. To define a statistically significant probability, $p$ values of less than 0.05 (95\% probability of significance) were accepted. SPSS version 20 was used for the analysis.

\section{RESULTS}

Table 2 presents the frequency and percentage of representation of the different PA domains in the children's TV programs in our sample. The most frequent indicators were sedentary or low activity behavior domains, plus active commuting, accounting for $81 \%$ ( $\mathrm{n}=$ $2316)$ and $13 \%(\mathrm{n}=359)$ of the total, respectively. Of the total sample, $3 \%(n=95)$ of the scenes portrayed household activities; $2 \%$ (n $=48)$, leisure-time PA; and $1 \%(n=25)$, other activities. There were no scenes for the occupational activity domain.
As shown in Table 3, there was a higher representation of male characters versus female characters in all PA domains $\left(\chi^{2}=278.58, \mathrm{df}=\right.$ $2, \mathrm{p}<.01)$. This effect size was moderate to large (Cramer's $\mathrm{V}=.313, \mathrm{p}<.05)$. In the 2516 scenes showing sedentary or low activity domains, $63 \%$ showed only male characters; $33 \%$, a group of both females and males; and $5 \%$, only females. Of the 359 scenes representing active commuting, $54 \%$ showed exclusively male characters; $31 \%$, exclusively females; and $15 \%$, a mixed-gender group. Of the 95 scenes representing household activities, $63 \%$ featured only male characters; $27 \%$, mixedgender groups; and $10 \%$, only females. None of the 48 scenes representing leisure-time PA showed only females; $93 \%$ of the scenes showed only males and 7\%, mixed-gender groups. Finally, of the 25 scenes identified in "other" PA domains, $80 \%$ showed female characters and $20 \%$, males.

Table 2

Frequencies and Percentages (\%) of images for specific activities in Physical Activity domains

\begin{tabular}{|c|c|c|c|c|c|}
\hline PA domains & \multicolumn{3}{|c|}{ Activities [n (\%)] } & & \multirow[t]{2}{*}{ Sub-total } \\
\hline $\begin{array}{l}\text { Sedentary behavior/low } \\
\text { activity }\end{array}$ & Standing motionless & Sitting activities & $\begin{array}{c}\text { Other } \\
\text { activities }\end{array}$ & & \\
\hline & $1434(62 \%)$ & $752(32 \%)$ & $130(6 \%)$ & & $2316(81 \%)$ \\
\hline \multirow{2}{*}{ Active commuting } & Walking & Bicycling & & & \\
\hline & $326(91 \%)$ & $32(9 \%)$ & & & $359(13 \%)$ \\
\hline \multirow{2}{*}{ Household activities } & Cooking & Washing-cleaning & Gardening & & \\
\hline & $33(34 \%)$ & $32(33 \%)$ & $31(33 \%)$ & & $95(3 \%)$ \\
\hline \multirow{2}{*}{$\begin{array}{l}\text { Leisure-time } \\
\text { activity }\end{array}$} & Physical exercise & $\begin{array}{c}\text { Leisure \& traditional } \\
\text { games }\end{array}$ & Sports & $\begin{array}{l}\text { Other } \\
\text { activities }\end{array}$ & \\
\hline & $29(60 \%)$ & $8(15 \%)$ & & $5(11 \%)$ & $48(2 \%)$ \\
\hline \multirow[t]{2}{*}{ Others } & \multirow{2}{*}{\multicolumn{4}{|c|}{ Total count: $2843(100 \%)$}} & $25(1 \%)$ \\
\hline & & & & & \\
\hline
\end{tabular}

Table 3

Scenes based on Physical Activity Domains: Contingency table for Physical Activity Domain for gender, group composition, and presence of a disability

\begin{tabular}{|c|c|c|c|c|c|c|}
\hline & $\begin{array}{c}\text { Sedentary } \\
\text { behavior/low activity }\end{array}$ & $\begin{array}{c}\text { Active } \\
\text { commuting }\end{array}$ & LTPA & $\begin{array}{l}\text { Household } \\
\text { activities }\end{array}$ & Other & $\chi^{2^{* *}}$ \\
\hline \multicolumn{7}{|l|}{ Gender } \\
\hline Male & $1449(63)$ & $195(54)$ & $45(93)$ & $60(63)$ & $5(20)$ & \multirow{3}{*}{$\begin{array}{c}278.576, d f=2 \\
p=0.001\end{array}$} \\
\hline Female & $109(5)$ & $110(31)$ & - & $10(10)$ & $20(80)$ & \\
\hline Mixed group & $758(33)$ & $54(15)$ & $3(6)$ & $25(27)$ & - & \\
\hline Group composition & & & & & & \multirow{3}{*}{$\begin{array}{c}4.680, d f=1 \\
p=0.035\end{array}$} \\
\hline Solitary & $518(22)$ & $140(39)$ & $28(58)$ & $40(42)$ & $22(88)$ & \\
\hline Group & $1798(78)$ & $219(61)$ & $20(42)$ & $55(58)$ & $3(12)$ & \\
\hline \multicolumn{7}{|l|}{ Presence of disability } \\
\hline Non-disability & 2316 & 359 & 48 & 95 & 25 & \\
\hline Disability & - & - & - & - & - & \\
\hline
\end{tabular}




\section{DISCUSSION}

Animated cartoons reflect and shape social values about children's behaviors and help to form children's initial notions of what it means to be passive or active (Byrd-Bredbenner, 2004; Folta et al., 2006; Outley \& Tadesse, 2006; Batada et al., 2006; Hentges \& Case, 2013; Kalayc, 2015; O'Reilly-Duff et al., 2018; Rozario et al., 2018; Streicher, 1974; Robinson \& Anderson, 2006; Thompson \& Zerbinos, 1995). Likewise, before early childhood and primary teachers can act to counteract negative messages and promote PA in the classroom, they must first understand the implicit messages transmitted through media content; our major aim was to gain knowledge about the representation of PA and sedentary behavior on Spanish children's cartoons. As suggested previously, careful examination of children's media content is important in order to address their potentially negative effects and educate consumers about what is being portrayed to their children (Baker \& Raney, 2007). In doing so, we analysed the most popular children's TV cartoons in Spain, examining the variables of gender, disability, and group composition. Here we discuss the general questions about the role of children's cartoons in promoting healthrelated behaviors that arose from our quantitative analysis, and finally, we offer several reflections and conclusions.

Our results suggest that current children's cartoons may favor an increase in SBs and a decrease in PA, undermining other health promotion messages regarding active behaviors. We agree with other authors calling for children's cartoons and commercials run during children's TV programs to portray children participating in more intense PA as a way to encourage them to be more active (Folta et al., 2006; Outley \& Tadesse, 2006). More recently, O'Reilly-Duff et al. (2018) found on four popular UK adolescent TV programmes that PA was portrayed infrequently, and often with a skewed representation of the type of activity.

Previous studies have shown that media content can influence children's beliefs, attitudes, and behaviors with regard to PA; thus, our results suggest that current children's cartoons may favor an increase in SBs and a decrease in PA, undermining other health promotion messages regarding active. In addition, we found that over $80 \%$ of the scenes in our sample depicted SB. This finding is consistent with other studies describing similar health-related content in diverse television media. For instance, Outley and Tadesse (2006) reported that only $9.4 \%$ of a sample of food advertisements shown during children's TV programming contained PA-related content. Moreover, $36.3 \%, 31.3 \%, 16.8 \%, 13.7 \%$, and $2.0 \%$ of all commercials advertised fast food restaurants, sugary drinks, candy, cereals, and snacks, respectively, reflecting considerable exposure to messages that contradict nutritional and PA guidelines. Recently, Davis (2016) found on a sample of North American commercials that $47.6 \%$ of them portrayed unhealthy food and none of them was for healthy food and drinks. Our analysis showed a large gap between the modest representation of different PA domains compared to the overwhelming depiction of SB, suggesting that children's cartoons serve to normalize sedentarism. In light of these findings, we agree with other authors calling for children's TV cartoons and commercials run during children's TV programs to portray children participating in more intense PA as a way to encourage them to be more active (Folta et al., 2006).

After analysing PA domains, it was found that the media gender gap still persists, as we did not find evidence of males and females participating equally in a variety of PA domains. In particular, we found that $62 \%$ of the scenes in cartoons show only males, compared to $9 \%$ showing only females and $29 \%$ showing mixedgender groups. In addition, boys and men were depicted in more physically active roles compared with females. For instance, we found that male characters were the main participants in $93 \%$ of scenes portraying leisure-time PA, and in $58 \%$ of these, a single male character performed the action. This is consistent with findings reported elsewhere; for instance, in one Turkish program targeted to children, male characters dominated the scenes showing PA and games (Kalayc, 2015). In addition, Gietzen 
et al. (2017) found in popular TV shows among adolescents in North America, that female characters tended to be underrepresented. Rozario et al. (2018) found on children's programming in India that more males than females were cast in all the character roles except in the role of the protagonist's family member, where both genders were cast equally (Rozario et al., 2018). In our study indeed, only male characters were shown riding a bicycle and swimming, suggesting a different pattern of PA for females and males in children's programming. Thus, young girls in Spain-as elsewhere-will see female models participating in sedentary or low activity domain behaviors and males participating in a range of leisuretime physical activities. This may lead both sexes to believe that leisure-time physical activities are gender-based. For instance, Coyne et al. (2016) found that engagement with Disney Princesses can be limiting, as young girls especially are more likely to embrace traditional female stereotypes both concurrently and longitudinally. Therefore, portraying female characters as more passive than males may potentially transmit harmful messages to young viewers. Thus, our results show that children's cartoons in Spain are not currently effective instruments for representing gender equality. In addition to limiting prolonged periods of SBs in children, parents, caregivers, and teachers could also use the children's TV programs to promote critical analysis and dialogue within and outside of the classroom.

Among school-aged learners, active commuting must be encouraged and integrated at a young age in order to be reinforced later (Larouche, R., \& Ghekiere, 2018). As suggested previously, children's programming on TV or cinema could play a positive role in increasing children's active transport to school (Tranter and Sharpe, 2012). Indeed, our results showed that active commuting had the second highest representation in the scenes, indicating a relatively positive role for this domain in children's cartoons despite the lower representation compared with SB. Moreover, and in contrast with Kalayc's (2015) findings regarding the gender gap shown in bicycle use in Turkish programming for children, we observed equal representation between male and female characters in active commuting.

By the other hand, taking into account that focusing on socio-cultural and environmental barriers rather than on the individual's impairment as suggested by the social model of disability (Saunders, 2004), consequently, in this manuscript, we aimed to address also how, taking into account disability category, people with and without disabilities are portrayed participating in a full range of PA and sedentary behaviors. In line with this, in our current study, we failed to identify any characters with disabilities in the sampled children's cartoons, reinforcing evidence on their invisibility in different media. Our findings are consistent with previous reports on this topic. In the United States, Bond (2013) found on children's television programming that people with a physical disability are still largely absent from the television landscape. In the same line, in Japan, one study found that only $1.7 \%$ of the characters analyzed had a disability, all of whom were adults (Saito \& Ishiyama, 2005).

Previous research has demonstrated that people with disabilities are under-represented on the walls of early childhood education classrooms in Spain as well as in printed curricular material used in Spanish physical education classes (Martínez-Bello \& MartínezBello, 2016; Martínez-Bello \& Molina-García, 2016). This literature argues that the imbalance in the representation of disability in the various contexts where PA takes place is symptomatic of the broader exclusion of disabled people across society, suggesting that the visual representations in the education context plays an important role in the construction of difference. In addition, taking into account that children sometimes watch cartoons in school (e.g., cartoons before recess), we believe that our results add further evidence elucidating the construction of difference in visual representations consumed by young children in Spain, this time through the most widely viewed children's cartoons. Our study also adds onto previous work, showing how children's TV cartoons in Spain reinforce differences through 
visual representations, not only in terms of the social model of disability but also in the lack of representation for PA promotion in people with a disability.

\section{Limitations and Further Research}

Assessing how children actually understand the visual messages transmitted through TV cartoons was beyond the scope of this study. However, considering the number of hours that children in Spain spend watching TV and their low compliance to guidelines on moderate to vigorous PA, the scarcity of health-related messages may suggest potential effects. In addition, another limitation of this study is that the coding procedure was done by consensus rather than independently. Although our study does not look at the relationship between PA or SB and television watching in children, it does describe the type of messages relating to PA that are shown in the most popular children's TV cartoons in Spain. Our study further contributes to the scientific literature by shedding light on the typical health-related behaviors coded in analyses of children's cartoons. However, the next step should also focus on qualitative methods to gain more understanding of how characters negotiate these meanings across PA domains. Taking into account that cartoon characters are used in food advertisements (Davis, 2016), future studies could focus on how PA domains are portrayed in Spanish food advertisement on weekend children's programming.

\section{CONCLUSION}

The present study suggests that current children's TV cartoons in Spain are not adequate in terms of promoting healthy behaviors related to PA. Spanish children are exposed to numerous representations of SBs on TV programs; these provide few positive healthrelated messages regarding PA to young people. We found that the media gender gap persists, as we did not find evidence of males and females participating equally in a variety of PA domains. In addition, our results showed that AC had the second highest representation in the scenes, indicating a relatively positive role for this domain in children's cartoons despite the lower representation compared with SB. Furthermore, we failed to identify any characters with disabilities in the sampled children's cartoons, reinforcing evidence on their invisibility in different media. Our results reinforce differences through visual representations, not only in terms of the social model of disability but also in the lack of representation for PA promotion in people with a disability.

While policymakers need to work on limiting sedentary time in pre-schoolers, early childhood practitioners, primary teachers, and families should also be aware of what kinds of messages children's TV programs are transmitting. Educators can thus propose programming alternatives for parents at home as well as address the stereotypes promoted in the media that children sometimes watch in school (e.g., cartoons before recess). Thus, the media and the educational community must work to develop educational projects capable of uniting the attraction to TV with training in active behaviors for all ages. Children, teachers, and parents should be encouraged to develop their critical thinking about the under-representation of health-related behaviors-including PA-on children's TV programs.

\section{Acknowledgments:}

Nothing to declare.

Conflict of interests:

Nothing to declare.

Funding:

Nothing to declare.

\section{REFERENCES}

American Academy of Pediatrics. (2016). Media use in school-aged children and adolescents. Pediatrics, 138(5), 1-5.

Baker, K., \& Raney, A. A. (2007). Equally super?: Gender-role stereotyping of superheroes in children's animated programs. Mass Communication \& Society, 10(1), 25-41.

Barlovento Comunicación. (2014). Informe audiencias tv enero 2014. Barlovento Comunicación. Retrieved from: 
http://www.barloventocomunicacion.es/blog/83 -informe-audiencias-tv-enero-2014.html.

Barner, M. R. (1999). Sex-role stereotyping in FCCmandated children's educational television. Journal of Broadcasting \& Electronic Media, 43(4), 551-564.

Barnett, T. A., O'Loughlin, J., \& Paradis, G. (2002). One-and two-year predictors of decline in physical activity among inner-city schoolchildren. American journal of preventive medicine, 23(2), 121-128.

Batada, A., Seitz, M. D., Wootan, M. G., \& Story, M. (2008). Nine out of 10 food advertisements shown during Saturday morning children's television programming are for foods high in fat, sodium, or added sugars, or low in nutrients. Journal of the American Dietetic Association, 108(4), 673-678.

Blumberg, R. L. (2015). Eliminating gender bias in textbooks: Pushing for policy reforms that promote gender equity in education. Background paper for EFA Global Monitoring Report. Paris: France, United Nations Educational, Scientific and Cultural Organization.

Bond, B. J. (2013). Physical disability on children's television programming: A content analysis. Early Education \& Development, 24(3), 408-418.

Byrd-Bredbenner, C. (2004). An internationally shared health frame of reference created by a television program: The Simpsons, a content analysis of health messages. Health Education, 104(1), 18-24.

Cardon, G., De Bourdeaudhuij, I., Iotova, V., Latomme, J., Socha, P., Koletzko, B., ... \& ToyBox-study group. (2016). Health related behaviours in normal weight and overweight preschoolers of a large pan-European sample: the ToyBox-study. PloS one, 11 (3), e0150580.

Chang, A., Schulz, P. J., Schirato, T., \& Hall, B. J. (2018). Implicit Messages Regarding Unhealthy Foodstuffs in Chinese Television Advertisements: Increasing the Risk of Obesity. International journal of environmental research and public health, 15(1), 70.

Coyne, S. M., Linder, J. R., Rasmussen, E. E., Nelson, D. A., \& Birkbeck, V. (2016). Pretty as a princess: Longitudinal effects of engagement with Disney princesses on gender stereotypes, body esteem, and prosocial behavior in children. Child Development, 87(6), 1909-1925.

Davis, D. (2016). A Content Analysis of Advertising on Children's Television Networks. Theses and Dissertations. 1801. Arkansas: University of Arkansas, Fayetteville.

De Craemer, M., Lateva, M., Iotova, V., De Decker, E., Verloigne, M., De Bourdeaudhuij, I., ... \& Koletzko, B. (2015). Differences in energy balance-related behaviours in European preschool children: the ToyBox-study. PLoS One, 10(3), e0118303.
Folta, S. C., Goldberg, J. P., Economos, C., Bell, R., \& Meltzer, R. (2006). Food advertising targeted at school-age children: A content analysis. Journal of nutrition education and behavior, 38(4), 244-248.

Fouts, G., Callan, M., Piasentin, K., \& Lawson, A. (2006). Demonizing in children's television cartoons and Disney animated films. Child psychiatry and human development, 37(1), 15-23.

Gietzen, M. S., Gollust, S. E., Linde, J. A., NeumarkSztainer, D., \& Eisenberg, M. E. (2017). A content analysis of physical activity in TV shows popular among adolescents. Research quarterly for exercise and sport, 88(1), 72-82.

Hallal, P. C., Martins, R. C., \& Ramírez, A. (2014). The Lancet Physical Activity Observatory: promoting physical activity worldwide. The Lancet, 384(9942), 471.

Hentges, B., \& Case, K. (2013). Gender Representations on Disney Channel, Cartoon Network, and Nickelodeon Broadcasts in the United States. Journal of Children and Media, 7(3), 319-333.

Hnatiuk, J. A., Salmon, J., Hinkley, T., Okely, A. D., \& Trost, S. (2014). A review of preschool children's physical activity and sedentary time using objective measures. American Journal of Preventive Medicine, 47(4), 487-497.

Krippendorff, K. (2004). Content analysis: An introduction to its methodology (2nd ed.). Thousand Oaks, CA: Sage.

Lambert, E. B. (2003). Introducing research to early childhood students. Victoria: Cengage Learning Australia.

Larouche, R., \& Ghekiere, A. (2018). An Ecological Model of Active Transportation. In Larouche, R. (ed). Children's Active Transportation. Elsevier, pp. 93-103.

Kalayci, N. (2015). Analyses of the Cartoon Series from a Gender Equality Perspective: Pepee. Egitim ve Bilim, 40(177), 243-270.

Kearney, A. (2011). How are disabled students excluded from and within school. In Exclusion from and within school (pp. 79-91). SensePublishers.

Marshall, S. J., Biddle, S. J., Sallis, J. F., McKenzie, T. L., \& Conway, T. L. (2002). Clustering of sedentary behaviors and physical activity among youth: a cross-national study. Pediatric exercise science, 14(4), 401-417.

Martin, R. (2017). Gender and Emotion Stereotypes in Children's Television. Journal of Broadcasting $\mathcal{E}$ Electronic Media, 61 (3), 499-517.

Martinez-Bello, V., \& Molina-Garcia, J. (2016). Representation of physical activity domains and sedentary behaviours in physical education textbooks: an image analysis. South African Journal for Research in Sport, Physical Education and Recreation, 38(2), 139-152.

Martínez-Bello, V. E., \& Martínez-Bello, J. T. (2016). Bodies displayed on walls: are children's bodies represented in an inclusive way in the pictures 
on the walls in their early childhood educational environments? Early Years, 37(2), 173-188.

O’Reilly-Duff, H., Best, P., \& Tully, M. A. (2018). Same old song and dance: an exploratory study of portrayal of physical activity in television programmes aimed at young adolescents. BMC research notes, 11(1), 458.

Outley, C. W., \& Taddese, A. (2006). A content analysis of health and physical activity messages marketed to African American children during after-school television programming. Archives of Pediatrics \& Adolescent Medicine, 160(4), 432-435.

Robinson, T., \& Anderson, C. (2006). Older characters in children's animated television programs: A content analysis of their portrayal. Journal of Broadcasting \& Electronic Media, 50(2), 287-304.

Rozario, A. M., Masilamani, V., \& Arulchelvan, S. (2018). The case of the missing girls: distribution of gender roles in Indian children's television programming. Journal of Children and Media, 12(2), 125-142.

Saito, S., \& Ishiyama, R. (2005). The invisible minority: under-representation of people with disabilities in prime-time TV dramas in Japan. Disability \& Society, 20(4), 437-451.

Sallis, J. F., \& Owen, N. (2015). Ecological models of health behavior. In Glanz, K., Rimer, B. K., \& Viswanath, K. (eds.). Health behavior: Theory, research, and practice. 5th ed. San Francisco: Jossey-Bass, pp. 43-64.

Saunders, K. (2004), "What disability studies can do for children's literature", Disability Studies Quarterly, Vol. 24 No.1, pp. 1-11.

Streicher, H. W. (1974). The girls in the cartoons. Journal of Communication, 24(2), 125129.

Thompson, T. L., \& Zerbinos, E. (1995). Gender roles in animated cartoons: Has the picture changed in 20 years?. Sex roles, 32 (9-10), 651-673.

Torres-Luque, G., Beltrán, J., Calahorro, F., LópezFernández, I., \& Nikolaidis, P. T. (2016). Analysis of the distribution of physical activity in early childhood education students. Cuadernos de Psicología del Deporte, 16(1), 261-268.

Tranter, P., \& Sharpe, S. (2012). Disney-Pixar to the rescue: harnessing positive affect for enhancing children's active mobility. Journal of transport geography, 20(1), 34-40.

Tremblay, M. S., Aubert, S., Barnes, J. D., Saunders, T. J., Carson, V., Latimer-Cheung, A. E., ... \& Chinapaw, M. J. (2017). Sedentary behavior research network (SBRN)-terminology consensus project process and outcome. International Journal of Behavioral Nutrition and Physical Activity, 14(1), 75.

United Nations Educational, Scientific, and Cultural Organization. (2017). A guide for ensuring inclusion and equity in education. Paris: UNESCO. 